\title{
Maternal fish consumption, fetal growth and the risks of neonatal complications: the Generation R Study
}

\author{
Denise H. M. Heppe ${ }^{1,2,3}$, Eric A. P. Steegers ${ }^{4}$, Sarah Timmermans ${ }^{1,4}$, Hanneke den Breeijen ${ }^{1,2}$, \\ Henning Tiemeier ${ }^{5}$, Albert Hofman ${ }^{2}$ and Vincent W. V. Jaddoe ${ }^{1,2,3_{*}}$ \\ ${ }^{1}$ The Generation R Study Group (Room Ae-012), Erasmus Medical Centre, PO Box 2040, 3000 CA Rotterdam, \\ The Netherlands \\ ${ }^{2}$ Department of Epidemiology, Erasmus Medical Centre, PO Box 2040, 3000 CA Rotterdam, The Netherlands \\ ${ }^{3}$ Department of Paediatrics, Erasmus Medical Centre, PO Box 2040, 3000 CA Rotterdam, The Netherlands \\ ${ }^{4}$ Department of Obstetrics and Gynaecology, Erasmus Medical Centre, PO Box 2040, 3000 CA Rotterdam, The Netherlands \\ ${ }^{5}$ Department of Child and Adolescent Psychiatry, Erasmus Medical Centre, PO Box 2040, 3000 CA Rotterdam, \\ The Netherlands \\ (Received 18 June 2010 - Revised 30 August 2010 - Accepted 27 September 2010 - First published online 26 January 2011)
}

\begin{abstract}
Maternal fish consumption during pregnancy has been suggested to affect birth outcomes. Previous studies mainly focused on birth outcomes and did not study fetal growth during pregnancy. In a prospective cohort study from early pregnancy onwards in The Netherlands, we assessed the associations of first-trimester maternal total-fish, lean-fish, fatty-fish and shellfish consumption with fetal growth characteristics in the second and third trimesters, growth characteristics at birth and the risks of neonatal complications, including pre-term birth, low birth weight and small for gestational age. In total, 3380 mothers completed a 293 -item semi-quantitative FFQ to obtain information about fish consumption during the first trimester of pregnancy. Head circumference, femur length and fetal weight were estimated in the second and third trimesters by ultrasound. Information about birth anthropometrics and neonatal complications was available from hospital and midwife registries. Maternal older age, higher educational level, folic acid supplement use, alcohol use and not smoking were associated with higher fish consumption $(P<0.01)$. After adjustment, we observed no consistent associations of maternal total-fish consumption or specific consumption of lean fish, fatty fish or shellfish with fetal growth characteristics in the second and third trimesters and at birth. Likewise, total-fish consumption or specific consumption of any type of fish was not consistently associated with the risks of neonatal complications. These findings suggest that in a population with a relatively low fish intake, consumption of lean fish, fatty fish or shellfish in the first trimester is not associated with fetal growth or the risks of neonatal complications.
\end{abstract}

Key words: Fish consumption: Pregnancy: Fetal growth: Neonatal complications

Maternal fish consumption during pregnancy has been suggested to affect pregnancy and birth outcomes ${ }^{(1-4)}$. Fish contains various nutrients considered to be beneficial for fetal growth and development, including polyunsaturated $n-3$ fatty acids, protein, selenium, iodine and vitamin $\mathrm{D}^{(5-7)}$. In particular, the $n-3$ fatty acids DHA and EPA have been associated with higher birth weight in both randomised controlled trials and observational studies ${ }^{(8,9)} \cdot n-3$ Fatty acids are hypothesised to affect eicosanoid synthesis. The down-regulation of $\mathrm{PG}_{2}$ production, which is related to initiation of the parturition process, has been suggested to increase pregnancy duration ${ }^{(10,11)}$. A shift of the prostacyclin/thromboxane A balance to a more anti-aggregatory and vasodilator state might increase placental flow and as a consequence fetal growth ${ }^{(12,13)}$. However, fish consumption is also a well-known route of exposure to pollutants such as methyl mercury, dioxins and polychlorinated biphenyls (PCB), which may adversely affect fetal growth and birth outcomes ${ }^{(14-17)}$. In a large study among Danish pregnant women, high maternal fish consumption was associated with lower birth weight, smaller birth length and head circumference $(\mathrm{HC})^{(18)}$. Thus far, results from studies focused on the associations between maternal fish consumption and birth outcomes have not been consistent $^{(9,19-22)}$. Differences in the results may be explained by specific effects of different types of fish, such as lean

Abbreviations: FL, femur length; HC, head circumference; PCB, polychlorinated biphenyls. 
fish, fatty fish and shellfish. Fatty fish contains larger amounts of beneficial $n-3$ fatty acid and, as with shellfish, higher levels of contaminants ${ }^{(16,23)}$. Besides, previous studies have mainly focused on birth outcomes as a measure of fetal growth and development. However, similar birth weights might be the result of different fetal exposures or growth patterns. Assessing fetal growth characteristics in different trimesters of pregnancy may provide information about specific critical periods.

Therefore, we examined the associations of firsttrimester maternal lean-fish, fatty-fish and shellfish consumption with fetal growth characteristics in the second and third trimesters and at birth and the risks of neonatal complications in a population-based prospective cohort study among 3380 mothers and their children.

\section{Methods}

\section{Study design}

The present study was embedded in the Generation $\mathrm{R}$ Study, a population-based prospective cohort study from fetal life until young adulthood in the city of Rotterdam, The Netherlands. The present study was designed to identify early environmental and genetic determinants of growth, development and health from fetal life until young adulthood, and has been described in detail previously ${ }^{(24,25)}$. Assessments during pregnancy included physical examinations, fetal ultrasounds, biological samples and questionnaires, and were planned in the first, second and third trimesters to collect information about fetal growth and its main determinants. The present study was performed in Dutch participants. Of the total group of Dutch mothers ( $n$ 4057), 98\% ( $n$ 3979) enrolled in the first or second trimester of pregnancy, and $87 \%$ ( $n$ 3456) fully completed the FFQ including all questions referring to fish consumption. Twin pregnancies ( $n$ 49), pregnancies leading to intra-uterine death ( $n$ 24) or without known birth outcomes ( $n$ 3) were excluded from the study population. The analyses were performed in the remaining 3380 subjects (Fig. 1). The study was approved by the Medical Ethics Committee of the Erasmus Medical Centre, Rotterdam. Written informed consent was obtained from all parents. The present study was conducted according to the guidelines laid down in the Declaration of Helsinki.

\section{Dietary assessment}

We assessed maternal dietary intake, including fish consumption, at enrolment in the study (median 13.5 weeks of gestation, total range 5.4-24.9 weeks) using a modified version of the validated semi-quantitative FFQ of KlipsteinGrobusch et al. ${ }^{(26)}$. This FFQ considered food intake over the prior 3 months, thereby covering dietary intake within the first trimester of pregnancy. The FFQ consists of 293 items structured to meal patterns. Questions include consumption frequency, portion size, preparation method and additions. Portion sizes were estimated using Dutch household measures and coloured photographs of foods showing different portion sizes ${ }^{(27)}$. To calculate average daily nutritional values, the 2006 version of the Dutch food composition table was used ${ }^{(28)}$. Frequency of fish consumption was assessed for total-fish consumption and different types of fish. Based on the nutrient content and information from previous studies, we assessed consumption of different fish types by seven categories: lean fish (codfish, plaice, catfish, sole fish, tuna, whiting and haddock), moderately fatty fish (trout, anchovy and gurnard), fatty fish (salmon, herring, mackerel, eel, sardines, halibut and bloater), shellfish (crab, lobster, shrimps and mussels), processed fish (fish fingers, fish burgers, crumbed and fried

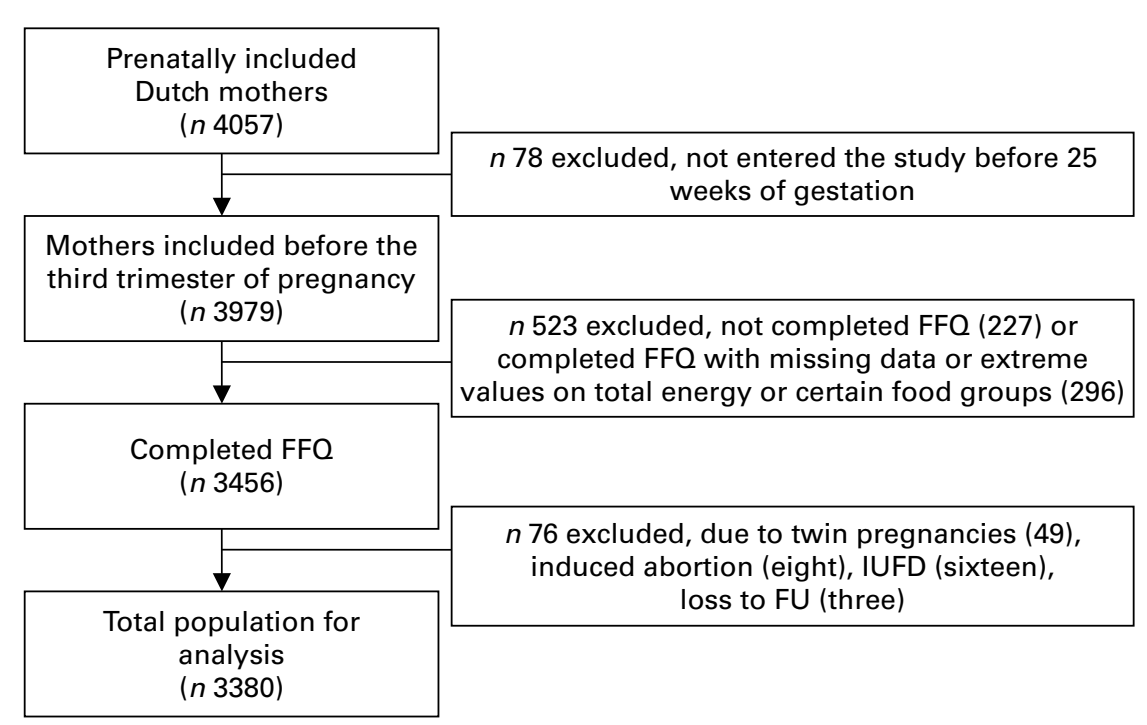

Fig. 1. Flow chart of participants included for analysis in the Generation R Study, Rotterdam, The Netherlands. IUFD, intrauterine fetal death; FU, follow-up. 
fish), fish derived from liver (haddock liver) and roe (soft and hard roe $)^{(18)}$. For the analysis of total fish, we aggregated all fish consumed, and for the analysis of fatty fish, we aggregated moderately fatty fish and fatty fish. Processed fish, roe and fish derived from liver were not further analysed separately.

\section{Fetal growth characteristics}

Fetal ultrasound examinations were carried out at one of the two research centres in each trimester of pregnancy. Median of these visits was 12.9 (total range $7 \cdot 7-18 \cdot 0$ ), 20.5 (total range $18 \cdot 0-25 \cdot 0$ ) and $30 \cdot 4$ (total range $25 \cdot 8-37 \cdot 0$ ) weeks of gestation for the first, second and third trimesters, respectively. These fetal ultrasound examinations were used for both establishing gestational age and assessing fetal growth characteristics ${ }^{(24)}$. Since gestational age was established by the first fetal ultrasound examination, these ultrasounds were not used to assess fetal growth. In the second and third trimesters of pregnancy, we measured HC, abdominal circumference (AC) and femur length (FL) to the nearest millimetre using standardised ultrasound procedures ${ }^{(29)}$. Estimated fetal weight (EFW) was calculated by means of the formula from Hadlock et $a l .{ }^{(30)}$ using $\mathrm{HC}, \mathrm{AC}$ and FL:

$$
\begin{aligned}
\log _{10} \mathrm{EFW}= & 1.5662-0.0108(\mathrm{HC})+0.0468(\mathrm{AC}) \\
& +0.171(\mathrm{FL})+0.00034(\mathrm{HC})^{2} \\
& -0.003685(\mathrm{AC} \times \mathrm{FL})
\end{aligned}
$$

\section{Neonatal complications}

Information about offspring sex, gestational age, weight, length and $\mathrm{HC}$ at birth was obtained from medical records and hospital registries. Since HC and length at birth were not routinely measured at birth, missing birth measures were completed with data from the first month visit at the routine child health centre. Of all measurements, 25 and $16 \%$ were based on the first month visit for $\mathrm{HC}$ and birth length, respectively. No differences in mean maternal fish consumption were observed between children with measurements at birth and those without measurements at birth ( $t$ tests: $P=0.46$ for HC and $P=0.94$ for birth length). The regression models with neonatal $\mathrm{HC}$ and length as outcome were adjusted for postconceptional age (gestational age for measurements at birth or gestational age + postnatal age for measurements from the child health centres) and for the method of measurements (birth or child health centre) ${ }^{(31)}$. Pre-term birth was defined as a gestational age of less than 37 weeks at delivery. Low birth weight was defined as birth weight below $2500 \mathrm{~g}$. Small size for gestational age at birth was defined as a gestational age and sex-adjusted birth weight below the 5 th percentile in the study cohort. We assessed both low birth weight and small for gestational age since it is important to differentiate between newborns having a low birth weight, independent of gestational age, and those who are fetally growth restricted. Both outcomes are independent risk factors of neonatal complications and development of diseases in adulthood ${ }^{(32,33)}$.

\section{Covariates}

Information about educational level, parity and periconceptional folic acid supplement use was obtained by a questionnaires at enrolment in the study. Maternal smoking and alcohol habits were assessed by questionnaires in each trimester. Maternal and paternal anthropometrics, including height $(\mathrm{m})$ and weight $(\mathrm{kg})$, were measured without shoes and heavy clothing, and BMI was calculated (weight/height ${ }^{2}\left(\mathrm{~kg} / \mathrm{m}^{2}\right)$ ) in the first, second and third trimesters during visits at the research centre. Information about maternal weight just before pregnancy was obtained by questionnaires. As enrolment in the present study was in pregnancy, we were not able to measure maternal weight before pregnancy. However, in our population for analysis, 56 and $85 \%$ of all women enrolled before a gestational age of 14 and 18 weeks, respectively. Correlation of prepregnancy weight obtained by questionnaires and weight measured at enrolment was $0.97(P<0.001)$. Since using weight measured at enrolment instead of pre-pregnancy weight obtained by questionnaires did not change the present results ${ }^{(34)}$, and considering the better data quality, we decided to use weight measured at enrolment in the analyses. Maternal age was registered at enrolment.

\section{Statistical analysis}

Based on the distribution of fish consumption and the number of subjects, we created five categories of total-fish consumption (0, 1-69, 70-139, 140-209 and $>210 \mathrm{~g} /$ week), four categories of lean-fish consumption $(0,1-34$, 35-69 and $>70 \mathrm{~g} /$ week), four categories of fatty-fish consumption $(0,1-34,35-69$ and $>70 \mathrm{~g} /$ week $)$ and three categories of shellfish consumption $(0,1-13$ and $>14 \mathrm{~g} /$ week). We used the category of 'no fish consumption' as the referent for all analyses. Analysis of total-fish consumption and consumption of lean fish, fatty fish and shellfish in quartiles and quintiles did not change the results. We used $t$ tests and $\chi^{2}$ tests to compare maternal characteristics in different categories of total weekly fish consumption. We analysed the associations of total weekly fish consumption with fetal growth characteristics in the second and third trimesters and at birth using multivariate linear regression models. In our first analyses, models were only adjusted for gestational age and fetal sex (model A). Subsequently, we considered confounders based on previous studies ${ }^{(15,16,18,19,21,22,31)}$. These 
Table 1. Maternal and fetal characteristics according to maternal fish consumption during pregnancy in the Generation R Study Cohort, Rotterdam, The Netherlands (Mean values and standard deviations or percentages)

\begin{tabular}{|c|c|c|c|c|c|c|c|c|c|c|c|c|c|c|c|c|c|c|c|}
\hline \multirow[b]{3}{*}{ Characteristics } & & & & \multicolumn{15}{|c|}{ Total weekly fish consumption (g/week) } & \multirow[b]{3}{*}{$P^{\star}$} \\
\hline & \multicolumn{3}{|c|}{ All $(n 3380)$} & \multicolumn{3}{|c|}{$0(n 668)$} & \multicolumn{3}{|c|}{$1-69(n 898)$} & \multicolumn{3}{|c|}{$70-139(n$ 1085) } & \multicolumn{3}{|c|}{$140-209(n 503)$} & \multicolumn{3}{|c|}{$>210(n 226)$} & \\
\hline & Mean & SD & $\%$ & Mean & SD & $\%$ & Mean & SD & $\%$ & Mean & SD & $\%$ & Mean & SD & $\%$ & Mean & SD & $\%$ & \\
\hline \multicolumn{20}{|l|}{ Maternal characteristics } \\
\hline Age (years) & 31.4 & 4.4 & & 30.1 & 4.7 & & 31.3 & 4.4 & & 31.8 & 4.0 & & $32 \cdot 2$ & 4.1 & & 31.8 & 4.3 & & $<0.01^{\star}$ \\
\hline Wt $(\mathrm{kg})$ & $70 \cdot 9$ & $12 \cdot 6$ & & 73.2 & 14.6 & & $70 \cdot 5$ & $12 \cdot 4$ & & $70 \cdot 0$ & 11.7 & & 70.5 & $12 \cdot 1$ & & $70 \cdot 2$ & $11 \cdot 3$ & & $<0.01^{*}$ \\
\hline $\mathrm{Ht}(\mathrm{cm})$ & 171 & 6.4 & & 171 & 6.7 & & 171 & $6 \cdot 1$ & & 171 & 6.4 & & 171 & $6 \cdot 3$ & & 171 & 6.5 & & 0.05 \\
\hline BMI $\left(\mathrm{kg} / \mathrm{m}^{2}\right)$ & $24 \cdot 3$ & $4 \cdot 1$ & & $25 \cdot 2$ & 4.9 & & $24 \cdot 2$ & 3.9 & & 23.9 & 3.7 & & 24.0 & 4.0 & & $23 \cdot 8$ & 3.7 & & $<0.01^{\star}$ \\
\hline Total energy intake (kJ) & 9007 & 2148 & & 8617 & 2262 & & 9013 & 2125 & & 9075 & 2058 & & 9322 & 2147 & & 9151 & 2147 & & $<0.01^{*}$ \\
\hline \multicolumn{20}{|l|}{ Marital status (\%) } \\
\hline Married & & & $45 \cdot 0$ & & & $46 \cdot 6$ & & & $45 \cdot 2$ & & & $46 \cdot 3$ & & & $42 \cdot 1$ & & & $40 \cdot 3$ & 0.19 \\
\hline Living together & & & $46 \cdot 3$ & & & $45 \cdot 3$ & & & $46 \cdot 1$ & & & $46 \cdot 1$ & & & $48 \cdot 7$ & & & 47.8 & \\
\hline No partner & & & 6.7 & & & 7.8 & & & $6 \cdot 8$ & & & $5 \cdot 6$ & & & $6 \cdot 2$ & & & $10 \cdot 2$ & \\
\hline Missing & & & 1.9 & & & $1 \cdot 0$ & & & 1.9 & & & $2 \cdot 0$ & & & $3 \cdot 0$ & & & $1 \cdot 8$ & \\
\hline \multicolumn{20}{|l|}{ Educational status (\%) } \\
\hline Primary school & & & 3.2 & & & 6.4 & & & 3.5 & & & 1.9 & & & 1.8 & & & 1.3 & $<0.01^{*}$ \\
\hline Secondary school & & & $37 \cdot 3$ & & & $50 \cdot 7$ & & & $40 \cdot 1$ & & & 32.5 & & & 28.4 & & & 29.5 & \\
\hline Higher education & & & 59.0 & & & $41 \cdot 8$ & & & $56 \cdot 1$ & & & $65 \cdot 2$ & & & $69 \cdot 2$ & & & $69 \cdot 2$ & \\
\hline Missing & & & 0.6 & & & $1 \cdot 0$ & & & 0.3 & & & 0.4 & & & 0.6 & & & 0.9 & \\
\hline \multicolumn{20}{|c|}{ Smoking during pregnancy (\%) } \\
\hline Never & & & 69.7 & & & $64 \cdot 2$ & & & 68.5 & & & $70 \cdot 9$ & & & 74.8 & & & 73.9 & $<0.01^{\star}$ \\
\hline $\begin{array}{l}\text { Until pregnancy was } \\
\text { known }\end{array}$ & & & $8 \cdot 0$ & & & $6 \cdot 1$ & & & $8 \cdot 5$ & & & 8.4 & & & $8 \cdot 2$ & & & $9 \cdot 7$ & \\
\hline Continued & & & $14 \cdot 7$ & & & $22 \cdot 2$ & & & $15 \cdot 0$ & & & $13 \cdot 3$ & & & 9.5 & & & 9.3 & \\
\hline \multirow{2}{*}{\multicolumn{20}{|c|}{ Alcohol use during pregnancy (\%) }} \\
\hline & & & & & & & & & & & & & & & & & & & \\
\hline Never & & & 31.3 & & & $46 \cdot 3$ & & & 29.8 & & & $27 \cdot 3$ & & & 24.9 & & & 28.6 & $<0.01^{*}$ \\
\hline $\begin{array}{l}\text { Until pregnancy was } \\
\text { known }\end{array}$ & & & $15 \cdot 3$ & & & $16 \cdot 0$ & & & $15 \cdot 6$ & & & $14 \cdot 7$ & & & $14 \cdot 9$ & & & $15 \cdot 9$ & \\
\hline Continued & & & $46 \cdot 1$ & & & $30 \cdot 7$ & & & $46 \cdot 7$ & & & $50 \cdot 7$ & & & 53.5 & & & $50 \cdot 4$ & \\
\hline Missing & & & $7 \cdot 3$ & & & 7.0 & & & $7 \cdot 9$ & & & $7 \cdot 3$ & & & $6 \cdot 8$ & & & $7 \cdot 1$ & \\
\hline $\begin{array}{l}\text { Folic acid supplement } \\
\text { use (\%) }\end{array}$ & & & & & & & & & & & & & & & & & & & $<0.01^{*}$ \\
\hline Preconception start & & & 46.4 & & & $44 \cdot 3$ & & & $45 \cdot 7$ & & & $47 \cdot 2$ & & & $49 \cdot 9$ & & & 44.7 & \\
\hline Postconception start & & & $27 \cdot 3$ & & & 23.4 & & & $27 \cdot 8$ & & & 28.7 & & & $27 \cdot 4$ & & & $29 \cdot 6$ & \\
\hline None & & & 8.9 & & & $15 \cdot 3$ & & & $6 \cdot 3$ & & & 7.6 & & & $7 \cdot 0$ & & & $10 \cdot 2$ & \\
\hline Missing & & & $17 \cdot 4$ & & & $17 \cdot 1$ & & & $20 \cdot 2$ & & & $16 \cdot 6$ & & & $15 \cdot 7$ & & & $15 \cdot 5$ & \\
\hline \multicolumn{20}{|l|}{ Fetal characteristics } \\
\hline \multicolumn{20}{|l|}{ Trimester 2} \\
\hline $\begin{array}{l}\text { Head } \\
\quad \text { circumference }(\mathrm{mm})\end{array}$ & 179 & 13 & & 179 & 13 & & 179 & 13 & & 179 & 13 & & 178 & 14 & & 180 & 14 & & 0.55 \\
\hline Femur length $(\mathrm{mm})$ & 33.4 & 3.3 & & 33.4 & 3.2 & & 33.3 & 3.3 & & 33.4 & 3.3 & & 33.1 & 3.3 & & 33.5 & 3.5 & & 0.32 \\
\hline Fetal wt (g) & 379 & 87 & & 379 & 84 & & 379 & 87 & & 381 & 85 & & 372 & 86 & & 386 & 93 & & 0.26 \\
\hline \multicolumn{20}{|l|}{ Trimester 3} \\
\hline $\begin{array}{l}\text { Head circumference } \\
(\mathrm{mm})\end{array}$ & 286 & 12 & & 284 & 13 & & 286 & 12 & & 286 & 12 & & 287 & 12 & & 286 & 12 & & $0.02^{*}$ \\
\hline Femur length (mm) & 57.5 & 2.9 & & 57.3 & 3.0 & & 57.5 & 3.0 & & 57.5 & $2 \cdot 8$ & & 57.6 & $2 \cdot 8$ & & 57.3 & 2.9 & & 0.49 \\
\hline Fetal wt $(\mathrm{g})$ & 1633 & 256 & & 1618 & 274 & & 1639 & 264 & & 1630 & 241 & & 1644 & 249 & & 1637 & 255 & & 0.57 \\
\hline Birth outcomes & & & & & & & & & & & & & & & & & & & \\
\hline $\begin{array}{l}\text { Males (\%) } \\
\text { Gestational age } \\
\text { (weeks) }\end{array}$ & 39.9 & 1.7 & 50.5 & 40.0 & 1.8 & $51 \cdot 8$ & 39.9 & 1.7 & $51 \cdot 2$ & $40 \cdot 0$ & 1.7 & $50 \cdot 0$ & $40 \cdot 1$ & $1 \cdot 6$ & 49.1 & 39.8 & $1 \cdot 8$ & 49.1 & $\begin{array}{l}0.86 \\
0.27\end{array}$ \\
\hline
\end{tabular}


confounders included maternal total daily energy intake, age, BMI, weight gain, parity, marital status, educational status, smoking, alcohol use, coffee consumption, nausea, vomiting, periconceptional folic acid use and paternal height. Potential confounders were included in the models if the effect estimates changed more than $5 \%$ in exploratory analyses. Using this approach, weight gain and parity were not included in the final multivariate analysis (model B). We performed similar analyses (models A and B) separately for consumption of lean fish, fatty fish and shellfish. We used logistic regression models to analyse the associations of total-fish, lean-fish, fatty-fish and shellfish consumption categories with the risks of neonatal complications (pre-term birth, low birth weight and small size for gestational age). Tests for trends were performed by using weekly consumption of total fish, lean fish, fatty fish and shellish as a continuous variable in the multivariate linear and logistic regression analyses. Multiple imputation was used to complete missing data on the covariates BMI (0.4\%), weight gain (3.3\%), educational status $(1 \cdot 9 \%)$, marital status $(0.6 \%)$, parity $(0.2 \%)$, smoking (7.6\%), alcohol use $(7 \cdot 3 \%)$, nausea $(7 \cdot 8 \%)$, vomiting (8.1\%) and folic acid supplement use (17.4\%). Since there were no differences in the observed results between analyses with imputed missing data or complete cases only, solely results including imputed missing data are presented. All measures of association are presented with their 95\% CI. $P$ values are two-sided. Statistical analyses were performed using the Predictive Analytic Software version 17.0 for Windows (PASW, Inc., Chicago, IL, USA).

\section{Results}

Maternal age ranged from 15.7 to 46.3 years, with a mean of 31.4 years (Tables 1 and 2). The median of total weekly fish consumption was 75 (total range 0-600) g. The median of weekly consumption of lean fish, fatty fish, shellfish and processed fish was 24 (total range $0-338) \mathrm{g}, 32$ (total range $0-360) \mathrm{g}, 0$ (total range $0-93$ ) g and 0 (total range $0-261) \mathrm{g}$, respectively.

Maternal older age, higher educational level, adequate folic acid supplement use, alcohol use and not smoking were associated with higher fish consumption $(P<0 \cdot 01)$. In the total cohort, the mean offspring birth weight was 3489 (SD 556) g, and the median gestational age at birth was 40.3 weeks (total range 26.7-43.4) weeks. Of all births, $4.7 \%$ were born pre-term, $4.0 \%$ had a low birth weight and $6.1 \%$ were small for gestational age at birth. Fetal growth characteristics measured during the second and third trimesters of pregnancy were available in 97.8 and $97.9 \%$ of the mothers, respectively.

Results from the gestational age and sex-adjusted regression models focused on the associations between fish consumption and fetal growth characteristics (model A) are given in the Supplementary materials (the supplementary material for this article can be found at 
Table 2. Associations between weekly maternal total-fish consumption and fetal growth and growth characteristics at birth in the Generation $\mathrm{R}$ Study Cohort, Rotterdam, The Netherlands*

(Differences and $95 \%$ confidence intervals)

\begin{tabular}{|c|c|c|c|c|c|c|c|c|c|}
\hline \multirow[b]{2}{*}{$\begin{array}{l}\text { Total-fish consumption } \\
\text { (g/week) }\end{array}$} & \multicolumn{3}{|c|}{ Trimester 2} & \multicolumn{3}{|c|}{ Trimester 3} & \multicolumn{3}{|c|}{ Birth } \\
\hline & $n$ & $\begin{array}{l}\text { Difference } \\
\quad(\mathrm{mm})\end{array}$ & $95 \% \mathrm{Cl}$ & $n$ & $\begin{array}{l}\text { Difference } \\
\quad(\mathrm{mm})\end{array}$ & $95 \% \mathrm{Cl}$ & $n$ & $\begin{array}{l}\text { Difference } \\
\quad(\mathrm{cm})\end{array}$ & $95 \% \mathrm{Cl}$ \\
\hline & \multicolumn{3}{|c|}{ Head circumference ( $n$ 3307) } & \multicolumn{3}{|c|}{ Head circumference ( $n$ 3276) } & \multicolumn{3}{|c|}{ Head circumference ( $n$ 2775) } \\
\hline 0 & 653 & Reference & & 641 & Reference & & 541 & Reference & \\
\hline $1-69$ & 878 & 0.4 & $-0.3,1.0$ & 872 & $1.3 \dagger$ & $0.3,2 \cdot 2$ & 742 & 0.2 & $-0.1,0.5$ \\
\hline $70-139$ & 1061 & -0.4 & $-1.0,0.2$ & 1058 & 0.1 & $-0.8,1.0$ & 895 & 0.0 & $-0.2,0.3$ \\
\hline $140-209$ & 494 & -0.2 & $-1.0,0.5$ & 487 & $1.2 \dagger$ & $0 \cdot 1,2 \cdot 3$ & 422 & 0.1 & $-0.2,0.4$ \\
\hline$>210$ & 221 & 0.2 & $-0.7,1.2$ & 218 & 0.9 & $-0.5,2.3$ & 175 & -0.0 & $-0.4,0.4$ \\
\hline$P$ for trend & \multicolumn{3}{|c|}{$\begin{array}{c}0.61 \\
\text { Femur length ( }(\text { 3306) }\end{array}$} & \multicolumn{3}{|c|}{$\begin{array}{c}0.24 \\
\text { Femur length }(n 3310)\end{array}$} & \multicolumn{3}{|c|}{$\begin{array}{c}0.39 \\
\text { Birth length }(n \text { 2831) }\end{array}$} \\
\hline 0 & 650 & Reference & & 652 & Reference & & 557 & Reference & \\
\hline $1-69$ & 877 & 0.1 & $-0.1,0.2$ & 879 & 0.1 & $-0.2,0.2$ & 758 & 0.3 & $-0.0,0.5$ \\
\hline $70-139$ & 1064 & -0.1 & $-0.2,0.1$ & 1067 & -0.0 & $-0.2,0.2$ & 911 & -0.1 & $-0.3,0.2$ \\
\hline $140-209$ & 494 & -0.1 & $-0.3,0.1$ & 492 & -0.0 & $-0.3,0.3$ & 428 & 0.1 & $-0.3,0.4$ \\
\hline$>210$ & 221 & 0.1 & $-0.2,0.3$ & 220 & -0.2 & $-0.5,0.2$ & 177 & -0.2 & $-0.7,0.2$ \\
\hline$P$ for trend & \multicolumn{3}{|c|}{$\begin{array}{c}0.87 \\
\text { Estimated fetal wt ( } n \text { 3291) }\end{array}$} & \multicolumn{3}{|c|}{$\begin{array}{c}0.61 \\
\text { Estimated fetal wt ( } n \text { 3298) }\end{array}$} & \multicolumn{3}{|c|}{$\begin{array}{c}0.26 \\
\text { Birth wt }(n 3367)\end{array}$} \\
\hline 0 & 647 & Reference & & 651 & Reference & & 667 & Reference & \\
\hline $1-69$ & 871 & 2.9 & $-1 \cdot 6,7 \cdot 3$ & 874 & $12 \cdot 6$ & $-6 \cdot 4,31 \cdot 6$ & 894 & $22 \cdot 0$ & $-22 \cdot 5,66 \cdot 4$ \\
\hline $70-139$ & 1061 & -0.5 & $-4 \cdot 8,3 \cdot 8$ & 1062 & -11.0 & $-29 \cdot 5,7.5$ & 1080 & $5 \cdot 1$ & $-38 \cdot 2,48 \cdot 4$ \\
\hline $140-209$ & 491 & -1.7 & $-6 \cdot 8,3.5$ & 491 & $1 \cdot 1$ & $-21 \cdot 1,23 \cdot 3$ & 501 & 17.4 & $-34 \cdot 6,69 \cdot 4$ \\
\hline$>210$ & 221 & 3.6 & $-3 \cdot 0,10 \cdot 3$ & 220 & $2 \cdot 1$ & $-26 \cdot 6,30 \cdot 9$ & 225 & $-3 \cdot 0$ & $-70.4,64.4$ \\
\hline$P$ for trend & & 0.94 & & & 0.63 & & & 0.86 & \\
\hline
\end{tabular}

* Values were based on multivariate linear regression models and reflect the difference and $95 \% \mathrm{Cl}$ for each level of total weekly fish consumption compared with the reference group $(0 \mathrm{~g} /$ week). All models were adjusted for maternal energy intake, age, BMl, marital status, education, smoking, alcohol use, nausea, vomiting, use of folic acid supplements, gestational age at measurement, paternal height and fetal sex. Tests for trend were performed by including total weekly fish consumption as a continuous term in the regression model.

$\dagger P<0.05$.

http://www.journals.cambridge.org/bjn). Higher consumption levels of total fish were associated with a larger thirdtrimester HC and birth length and a lower risk of low birth weight. Consumption of lean fish was positively associated with the third-trimester HC and birth weight and inversely associated with the risk of small for gestational age. A higher level of fatty-fish consumption was also inversely associated with the risk of small for gestational age. A higher shellfish consumption level was associated with larger FL in the second trimester.

After additional adjustment for confounders, most associations disappeared. The differences between model $\mathrm{A}$ and model B were largely explained by various factors including smoking, educational status and folic acid supplement use in the regression models. The results are shown in Tables 3-6. As compared to no fish consumption, weekly maternal consumption of 0-69 and 140-209g of total fish was associated with larger HC measured in the third trimester (both $P$ values $<0.05$ ). The test for trend, however, was NS. No associations were observed between maternal total-fish consumption and other fetal growth characteristics in the second and third trimesters or at birth. Weekly consumption of lean fish and fatty fish was not associated with fetal growth characteristics in the second and third trimesters or at birth. Weekly consumption of $>14 \mathrm{~g}$ of shellfish was associated with lower birth weight $(P=0 \cdot 04)$. Shellfish consumption was not associated with other fetal growth characteristics. Maternal consumption of total fish, fatty fish, lean fish or shellfish was not consistently associated with the risk of children born pre-term, with a low birth weight or small size for gestational age.

\section{Discussion}

\section{Main findings}

In this cohort of pregnant women in The Netherlands, we found no consistent associations of total-fish, lean-fish or fatty-fish consumption with fetal growth characteristics during the second and third trimesters and at birth, after adjustment for potential confounders. Shellfish consumption was not associated with fetal growth characteristics during the second and third trimesters; however, some evidence was found for an association between shellfish consumption and lower birth weight. No consistent associations were observed between fish consumption and the risks of neonatal complications. The median of weekly fish consumption in the present study population was $75 \mathrm{~g}$, which is higher than the median fish consumption presented in a Dutch cohort study ( $52 \mathrm{~g} /$ week) and measured by the Dutch National Food Consumption Survey $(63 \mathrm{~g} /$ week $)$ in a population of similar age ${ }^{(35,36)}$ These differences may be due to the differences in the time period, since data on fish consumption were collected between 1993 and 1998. Mean fish consumption in the 
Table 3. Associations between weekly maternal lean-fish consumption and fetal growth and growth characteristics at birth in the Generation R Study Cohort, Rotterdam, The Netherlands*

(Differences and 95\% confidence intervals)

\begin{tabular}{|c|c|c|c|c|c|c|c|c|c|}
\hline \multirow[b]{2}{*}{$\begin{array}{l}\text { Lean-fish consumption } \\
\text { (g/week) }\end{array}$} & \multicolumn{3}{|c|}{ Trimester 2} & \multicolumn{3}{|c|}{ Trimester 3} & \multicolumn{3}{|c|}{ Birth } \\
\hline & $n$ & $\begin{array}{l}\text { Difference } \\
\quad(\mathrm{mm})\end{array}$ & $95 \% \mathrm{Cl}$ & $n$ & $\begin{array}{l}\text { Difference } \\
\quad(\mathrm{mm})\end{array}$ & $95 \% \mathrm{Cl}$ & $n$ & $\begin{array}{l}\text { Difference } \\
\quad(\mathrm{cm})\end{array}$ & $95 \% \mathrm{Cl}$ \\
\hline & \multicolumn{3}{|c|}{ Head circumference ( $n$ 3307) } & \multicolumn{3}{|c|}{ Head circumference ( $n$ 3276) } & \multicolumn{3}{|c|}{ Head circumference ( $n$ 2775) } \\
\hline 0 & 1239 & Ref & & 1219 & Ref & & 1017 & Ref & \\
\hline $1-35$ & 849 & 0.1 & $-0.5,0.6$ & 850 & 0.4 & $-0.5,1.2$ & 724 & -0.0 & $-0.2,0.2$ \\
\hline $35-69$ & 813 & -0.0 & $-0.6,0.5$ & 804 & 0.6 & $-0.2,1.4$ & 697 & 0.1 & $-0.2,0.2$ \\
\hline$>70$ & 406 & -0.0 & $-0.7,0.7$ & 403 & -0.2 & $-1 \cdot 2,0 \cdot 8$ & 337 & -0.1 & $-0.3,0.2$ \\
\hline$P$ for trend & \multicolumn{3}{|c|}{$\begin{array}{l}0.78 \\
\text { Femur length }(n 3306)\end{array}$} & \multicolumn{3}{|c|}{$\begin{array}{l}\quad 0.40 \\
\text { Femur length }(n 3310)\end{array}$} & \multicolumn{3}{|c|}{$\begin{array}{l}0.76 \\
\text { Birth length ( } n \text { 2831) }\end{array}$} \\
\hline 0 & 1233 & Ref & & 1234 & Ref & & 1044 & Ref & \\
\hline $1-35$ & 853 & 0.1 & $-0.1,0.2$ & 857 & 0.1 & $-0.1,0.3$ & 742 & 0.2 & $-2 \cdot 3,2 \cdot 7$ \\
\hline $35-69$ & 810 & -0.1 & $-0.2,0.1$ & 812 & 0.1 & $-0.2,0.3$ & 711 & -0.1 & $-2 \cdot 7,2 \cdot 4$ \\
\hline$>70$ & 406 & -0.1 & $-0.3,0.1$ & 407 & -0.1 & $-0.4,0.1$ & 334 & -1.5 & $-4 \cdot 7,1 \cdot 8$ \\
\hline \multirow[t]{2}{*}{$P$ for trend } & \multirow{2}{*}{\multicolumn{3}{|c|}{$\begin{array}{c}0.49 \\
\text { Estimated fetal wt ( } n \text { 3291) }\end{array}$}} & & 0.41 & & & 0.56 & \\
\hline & & & & \multicolumn{3}{|c|}{ Estimated fetal wt ( $n$ 3298) } & \multicolumn{3}{|c|}{ Birth wt ( $n$ 3367) } \\
\hline 0 & 1226 & Ref & & 1230 & Ref & & 1262 & Ref & \\
\hline $1-35$ & 849 & 0.7 & $-3 \cdot 1,4 \cdot 5$ & 852 & $4 \cdot 2$ & $-12 \cdot 3,20 \cdot 7$ & 869 & $13 \cdot 2$ & $-25 \cdot 4,51 \cdot 8$ \\
\hline $35-69$ & 810 & -1.4 & $-5 \cdot 4,2 \cdot 5$ & 810 & $6 \cdot 6$ & $-10 \cdot 3,23 \cdot 5$ & 823 & $25 \cdot 3$ & $-14 \cdot 3,64 \cdot 9$ \\
\hline$>70$ & 406 & -0.4 & $-5.3,4.5$ & 406 & -5.9 & $-27 \cdot 1,15 \cdot 2$ & 413 & -30.2 & $-79 \cdot 7,19 \cdot 3$ \\
\hline$P$ for trend & & 0.64 & & & 0.96 & & & 0.84 & \\
\hline
\end{tabular}

Ref, reference.

* Values were based on multivariate linear regression models for each level of weekly lean-fish consumption compared with the reference group (0 g/week). All models were adjusted for maternal energy intake, age, BMI, marital status, education, smoking, alcohol use, nausea, vomiting, use of folic acid supplements, gestational age at measurement, paternal height and fetal sex. Tests for trend were performed by including weekly lean-fish consumption as a continuous term in the regression model.

present study was comparable to mean fish consumption in The Netherlands reported in a more recent study comparing fish consumption between European countries $(13.4 \mathrm{~g} / \mathrm{d}$ in the present study and $12.6-14.8 \mathrm{~g} / \mathrm{d}$ in the European Investigation into Cancer and Nutrition study) ${ }^{(37)}$.

\section{Interpretation of the main findings}

To our knowledge, only one previous study has assessed the associations of total-fish consumption with fetal growth characteristics in the second and third trimesters ${ }^{(21)}$. The present study among 1805 pregnant women in France did not show associations between total-seafood consumption and fetal growth characteristics. Many studies have assessed the associations of consumption of different types of fish with birth outcomes as measures for fetal development. In a large cohort in Denmark, no association was observed between lean-fish consumption and the risks of adverse birth outcomes. However, associations were observed between frequent consumption of fatty fish with lower birth weight and smaller birth length and $\mathrm{HC}^{(18)}$. Frequent fatty-fish consumption was also associated with a higher risk of small size for gestational age at birth. Also, higher total-fish consumption levels were associated with lower birth weight and smaller HC, which seems to be fully explained by the consumption of fatty fish. In the present study, we did not find consistent associations of total-fish or fatty-fish consumption with fetal growth characteristics. This difference in the results might be due to the differences in quality and quantity of fish consumption. In our population, mean total-fish consumption was much lower than in Denmark. A daily consumption of $>40$ or $>60 \mathrm{~g} / \mathrm{d}$ was reported by 14 and $6 \%$ in the Danish population, as compared with 3 and $1 \%$ in the present study population.

Differences in the quantity of types of fish consumed complicate a direct comparison of the results between countries ${ }^{(37)}$. A recent study in Spain showed an association between weekly consumption of $\geq 2$ portions of large oily fish and a higher risk of small size for gestational age. The authors also described an association of highlean-fish consumption with a lower risk of small size for gestational age ${ }^{(16)}$. Mean consumption levels of large oily fish or lean fish were not presented, but the mean totalfish consumption in the present study was $65 \mathrm{~g} / \mathrm{d}$, compared with $13 \mathrm{~g} / \mathrm{d}$ in our Dutch population. Another Spanish study showed that consumption of $>1$ portion of crustaceans per week was associated with a higher risk of small size for gestational age ${ }^{(38)}$. A French study showed the same association with consumption of $>2$ portions of shellfish per week ${ }^{(23)}$. In the Spanish study, mean consumption of crustaceans was 6.3 and $13.1 \mathrm{~g} / \mathrm{d}$ for other types of shellfish; in the French study, mean consumption of shellfish was $19.7 \mathrm{~g} / \mathrm{d}$. In the present study population, shellfish were barely consumed at all. Nevertheless, a tendency towards a negative association of shellfish consumption with birth weight was observed. This association has been reported previously. It is therefore important to explore which type of shellfish contributes to this effect. It is most likely that this association is driven by large crustaceans (crabs, lobster, etc.), since 
Table 4. Associations between weekly maternal fatty-fish consumption and fetal growth and growth characteristics at birth in the Generation R Study Cohort, Rotterdam, The Netherlands*

(Differences and $95 \%$ confidence intervals)

\begin{tabular}{|c|c|c|c|c|c|c|c|c|c|}
\hline \multirow{3}{*}{$\begin{array}{l}\text { Fatty-fish consumption } \\
\text { (g/week) }\end{array}$} & \multicolumn{3}{|c|}{ Trimester 2} & \multicolumn{3}{|c|}{ Trimester 3} & \multicolumn{3}{|c|}{ Birth } \\
\hline & & Difference & & & Difference & & & ifferenc & \\
\hline & $n$ & $(\mathrm{~mm})$ & $95 \% \mathrm{Cl}$ & $n$ & $(\mathrm{~mm})$ & $95 \% \mathrm{Cl}$ & $n$ & $(\mathrm{~cm})$ & $95 \% \mathrm{Cl}$ \\
\hline & \multicolumn{3}{|c|}{ Head circumference ( $n$ 3307) } & \multicolumn{3}{|c|}{ Head circumference ( $n$ 3276) } & \multicolumn{3}{|c|}{ Head circumference ( $n$ 2775) } \\
\hline 0 & 1083 & Ref & & 1064 & Ref & & 912 & Ref & \\
\hline $1-35$ & 719 & -0.0 & $-0.6,0.6$ & 725 & 0.6 & $-0.3,1.4$ & 610 & 0.0 & $-0.2,0.3$ \\
\hline $35-69$ & 911 & -0.4 & $-1 \cdot 0,0.2$ & 900 & -0.3 & $-1 \cdot 1,0.6$ & 764 & -0.1 & $-0.3,0.1$ \\
\hline$>70$ & 594 & -0.4 & $-1 \cdot 0,0 \cdot 3$ & 587 & -0.4 & $-0.5,1.4$ & 489 & -0.1 & $-0.3,0.2$ \\
\hline \multirow[t]{2}{*}{$P$ for trend } & \multirow{2}{*}{\multicolumn{3}{|c|}{$\begin{array}{c}0.29 \\
\text { Femur length }(n 3306)\end{array}$}} & \multicolumn{3}{|c|}{0.37} & \multicolumn{3}{|c|}{0.43} \\
\hline & & & & & emur length & & & th length & 331) \\
\hline 0 & 1079 & Ref & & 1081 & Ref & & 934 & Ref & \\
\hline $1-35$ & 723 & -0.0 & $-0.2,0.1$ & 729 & -0.0 & $-0.2,0.2$ & 626 & 0.1 & $-0.2,0.3$ \\
\hline $35-69$ & 911 & -0.1 & $-0.2,0.1$ & 908 & -0.1 & $-0.3,0.1$ & 774 & -0.1 & $-0.3,0.2$ \\
\hline$>70$ & 593 & -0.1 & $-0.3,0.1$ & 592 & -0.1 & $-0.3,0.2$ & 497 & -0.1 & $-0.4,0.2$ \\
\hline \multirow[t]{2}{*}{$P$ for trend } & & 0.57 & & & 0.45 & & & 0.29 & \\
\hline & \multicolumn{3}{|c|}{ Estimated fetal wt ( $n$ 3291) } & \multicolumn{3}{|c|}{ Estimated fetal wt ( $n$ 3298) } & \multicolumn{3}{|c|}{ Birth wt ( $n$ 3367) } \\
\hline 0 & 1074 & Ref & & 1077 & Ref & & 1100 & Ref & \\
\hline $1-35$ & 719 & -0.7 & $-4 \cdot 7,3 \cdot 4$ & 725 & $-1 \cdot 3$ & $-18 \cdot 8,16 \cdot 2$ & 737 & $-11 \cdot 7$ & $-52 \cdot 8,29 \cdot 3$ \\
\hline $35-69$ & 910 & $-1 \cdot 7$ & $-5 \cdot 6,2 \cdot 2$ & 907 & $-13 \cdot 6$ & $-30 \cdot 3,3 \cdot 1$ & 928 & 4.5 & $-34 \cdot 8,43 \cdot 8$ \\
\hline$>70$ & 588 & $-2 \cdot 7$ & $-7 \cdot 2,1 \cdot 7$ & 589 & -11.5 & $-30 \cdot 5,7 \cdot 6$ & 602 & -8.4 & $-53 \cdot 3,36 \cdot 4$ \\
\hline$P$ for trend & & 0.31 & & & 0.27 & & & 0.83 & \\
\hline
\end{tabular}

Ref, reference.

* Values were based on multivariate linear regression models for each level of weekly fatty-fish consumption compared with the reference group ( $0 \mathrm{~g} /$ week). All models were adjusted for maternal energy intake, age, BMI, marital status, education, smoking, alcohol use, nausea, vomiting, use of folic acid supplements, gestational age at measurement, paternal height and fetal sex. Tests for trend were performed by including weekly fatty-fish consumption as a continuous term in the regression model.

they are known to contain more dioxins and PCB. However, we were not able to separately analyse different types of shellfish, since we assessed shellfish by a predefined category. Therefore, this association needs to be studied in further detail.

Strong associations of higher fish consumption with increased growth measures at birth have mainly been described in ecological and cohort studies that collected data in the 1980s and 1990s in countries that have a high seafood consumption ${ }^{(1-4,39,40)}$. Results from large cohorts conducted more recently have suggested the absence of any association or inverse associations. Since not only in the present study, but also in other cohort studies, high fish consumption was strongly related to a higher education level and more healthy lifestyle habits ${ }^{(16,18,21,41)}$, these positive associations between fish consumption and

Table 5. Associations between weekly maternal shellfish consumption and fetal growth and growth characteristics at birth in the Generation R Study Cohort, Rotterdam, The Netherlands*

(Differences and $95 \%$ confidence intervals)

\begin{tabular}{|c|c|c|c|c|c|c|c|c|c|}
\hline \multirow[b]{2}{*}{$\begin{array}{l}\text { Shellfish consumption } \\
\text { (g/week) }\end{array}$} & \multicolumn{3}{|c|}{ Trimester 2} & \multicolumn{3}{|c|}{ Trimester 3} & \multicolumn{3}{|c|}{ Birth } \\
\hline & $n$ & $\begin{array}{l}\text { Difference } \\
(\mathrm{mm})\end{array}$ & $95 \% \mathrm{Cl}$ & $n$ & $\begin{array}{l}\text { Difference } \\
(\mathrm{mm})\end{array}$ & $95 \% \mathrm{Cl}$ & $n$ & $\begin{array}{l}\text { Difference } \\
\quad(\mathrm{cm})\end{array}$ & $95 \% \mathrm{Cl}$ \\
\hline & \multicolumn{3}{|c|}{ Head circumference ( $n$ 3307) } & \multicolumn{3}{|c|}{ Head circumference ( $n$ 3276) } & \multicolumn{3}{|c|}{ Head circumference ( $n$ 2775) } \\
\hline 0 & 2053 & Ref & & 2027 & Ref & & 1693 & Ref & \\
\hline $1-13$ & 604 & 0.2 & $-0.4,0.8$ & 609 & 0.8 & $-0.04,1.64$ & 521 & -0.0 & $-0.3,0.2$ \\
\hline$>14$ & 650 & -0.0 & $-0.6,0.5$ & 640 & -0.3 & $-1.16,0.48$ & 561 & -0.1 & $-0.3,0.2$ \\
\hline$P$ for trend & \multicolumn{3}{|c|}{$\begin{array}{l}0.72 \\
\text { Femur length ( } n 3306)\end{array}$} & \multicolumn{3}{|c|}{$\begin{array}{l}0.58 \\
\text { Femur length }(n 3310)\end{array}$} & \multicolumn{3}{|c|}{ Birth length ( $n$ 2831) } \\
\hline 0 & 2049 & Ref & & 2046 & Ref & & 1747 & Ref & \\
\hline $1-13$ & 608 & -0.0 & $-0.2,0.1$ & 618 & 0.0 & $-0.2,0.2$ & 528 & -0.0 & $-0.3,0.3$ \\
\hline$>14$ & 649 & -0.1 & $-0.3,0.1$ & 646 & -0.2 & $-0.4,0.0$ & 556 & -0.1 & $-0.4,0.1$ \\
\hline$P$ for trend & \multicolumn{3}{|c|}{$\begin{array}{l}0.53 \\
\text { Estimated fetal wt ( } n \text { 3291) }\end{array}$} & \multicolumn{3}{|c|}{$\begin{array}{l}\quad 0.21 \\
\text { Estimated fetal wt ( } n \text { 3298) }\end{array}$} & \multicolumn{3}{|c|}{$\begin{array}{l}0.35 \\
\text { Birth wt ( } n \text { 3367) }\end{array}$} \\
\hline 0 & 2042 & Ref & & 2040 & Ref & & 2090 & Ref & \\
\hline $1-13$ & 604 & $-1 \cdot 0$ & $-4 \cdot 9,3.0$ & 615 & $4 \cdot 1$ & $-12 \cdot 7,20 \cdot 8$ & 620 & $-10 \cdot 6$ & $-50 \cdot 1,29 \cdot 0$ \\
\hline$>14$ & 645 & -0.3 & $-4 \cdot 2,3 \cdot 6$ & 643 & -14.8 & $-31 \cdot 6,2 \cdot 1$ & 657 & $-41 \cdot 7 \dagger$ & $-81 \cdot 2,-2 \cdot 2$ \\
\hline$P$ for trend & & 0.82 & & & 0.15 & & & 0.07 & \\
\hline
\end{tabular}

Ref, reference.

* Values were based on multivariate linear regression models for each level of weekly shellfish consumption compared with the reference group (0 g/week). All models were adjusted for maternal energy intake, age, BMI, marital status, education, smoking, alcohol use, nausea, vomiting, use of folic acid supplements, gestational age at measurement, paternal height and fetal sex. Tests for trend were performed by including weekly shellfish consumption as a continuous term in the regression model.

$\dagger P<0.05$. 
Table 6. Associations between fish consumption and the risks of neonatal complications in the Generation R Study Cohort, Rotterdam, The Netherlands*

(Odds ratios and $95 \%$ confidence intervals)

\begin{tabular}{|c|c|c|c|c|c|c|c|c|c|c|c|c|}
\hline \multirow[b]{3}{*}{ Fish consumption } & \multicolumn{12}{|c|}{ Neonatal complications } \\
\hline & \multicolumn{4}{|c|}{ Pre-term birth ( $n$ 159) } & \multicolumn{4}{|c|}{ Low birth wt ( $n$ 138) } & \multicolumn{4}{|c|}{ Small for gestational age ( $n$ 205) } \\
\hline & $n$ & Cases & OR & $95 \% \mathrm{Cl}$ & $n$ & Cases & OR & $95 \% \mathrm{Cl}$ & $n$ & Cases & OR & $95 \% \mathrm{Cl}$ \\
\hline \multicolumn{13}{|c|}{ Total-fish consumption ( $\mathrm{g} /$ week) } \\
\hline 0 & 668 & 34 & Ref & & 667 & 34 & Ref & & 667 & 51 & Ref & \\
\hline $1-69$ & 897 & 45 & $1 \cdot 14$ & $0.71,1.82$ & 894 & 29 & $0.47 \dagger$ & $0.23,0.95$ & 893 & 57 & 0.87 & $0.58,1.30$ \\
\hline $70-139$ & 1085 & 47 & 0.98 & $0.61,1.57$ & 1080 & 46 & 0.78 & $0.42,1.44$ & 1079 & 60 & 0.76 & $0.51,1.14$ \\
\hline $140-209$ & 502 & 20 & 0.92 & $0.51,1.65$ & 501 & 16 & 0.62 & $0.27,1.40$ & 501 & 25 & 0.68 & $0.41,1 \cdot 14$ \\
\hline$>210$ & 226 & 13 & 1.21 & $0.61,2.38$ & 225 & 13 & 0.86 & $0.34,2 \cdot 17$ & 225 & 12 & 0.67 & $0.34,1.30$ \\
\hline$P$ for trend & & & 0.82 & & & & 0.89 & & & & 0.19 & \\
\hline \multicolumn{13}{|c|}{ Lean-fish consumption (g/week) } \\
\hline 0 & 1267 & 75 & Ref & & 1262 & 62 & Ref & & 1260 & 91 & Ref & \\
\hline $1-35$ & 869 & 32 & 0.68 & $0.44,1.05$ & 869 & 27 & 0.66 & $0.35,1.25$ & 869 & 46 & 0.75 & $0.51,1 \cdot 10$ \\
\hline $35-69$ & 828 & 38 & 0.84 & $0.55,1.28$ & 823 & 32 & 0.81 & $0.43,1.51$ & 823 & 37 & 0.67 & $0.44,1.00$ \\
\hline$>70$ & 414 & 14 & 0.61 & $0.33,1.10$ & 413 & 17 & 1.22 & $0.58,2.54$ & 413 & 31 & 1.15 & $0.73,1.79$ \\
\hline$P$ for trend & & & $0 \cdot 15$ & & & & 0.91 & & & & 0.92 & \\
\hline \multicolumn{13}{|c|}{ Fatty-fish consumption (g/week) } \\
\hline 0 & 1104 & 58 & Ref & & 1100 & 50 & Ref & & 1099 & 75 & Ref & \\
\hline $1-35$ & 739 & 26 & 0.70 & $0.43,1.12$ & 737 & 18 & 0.66 & $0.33,1.31$ & 737 & 51 & 1.00 & $0.68,1.46$ \\
\hline $35-69$ & 931 & 48 & 1.04 & $0.69,1.57$ & 928 & 47 & 1.23 & $0.69,2.19$ & 927 & 49 & 0.77 & $0.52,1.14$ \\
\hline$>70$ & 604 & 27 & 0.87 & $0.54,1.42$ & 602 & 23 & 1.00 & $0.50,1.98$ & 602 & 30 & 0.71 & $0.45,1.12$ \\
\hline$P$ for trend & & & 0.87 & & & & 0.81 & & & & 0.06 & \\
\hline \multicolumn{13}{|c|}{ Shellfish consumption (g/week) } \\
\hline 0 & 2098 & 103 & Ref & & 2090 & 87 & Ref & & 2089 & 120 & Ref & \\
\hline $1-13$ & 620 & 24 & 0.84 & $0.53,1.33$ & 620 & 18 & 0.88 & $0.45,1.72$ & 620 & 44 & 1.21 & $0.85,1.78$ \\
\hline$>14$ & 660 & 32 & $1 \cdot 15$ & $0.75,1.75$ & 657 & 33 & 1.72 & $0.95,3.07$ & 656 & 41 & 1.20 & $0.83,1.80$ \\
\hline$P$ for trend & & & 0.16 & & & & 0.90 & & & & 0.80 & \\
\hline
\end{tabular}

Ref, reference.

* Values were based on multivariate logistic regression models for pregnancy complications for each level of fish consumption compared with the reference group $(0 \mathrm{~g} /$ week). All models were adjusted for maternal energy intake, age, BMI, marital status, education, smoking, alcohol use, nausea, vomiting, use of folic acid supplements, gestational age at measurement, paternal height and fetal sex. Tests for trend were performed by including weekly fish consumption as a continuous term in the regression model. $\dagger P<0.05$.

birth anthropometrics may be partly due to residual confounding by lifestyle-related characteristics. However, in a Danish study conducted in 2002, the association of fish consumption with a lower risk of pre-term birth and having a low birth weight remained significant after adjustment for confounders. Also, in a British study, the association of fish consumption with a lower risk of fetal growth retardation remained significant after adjustment for maternal education.

Contamination of fish has frequently been suggested as explanation for the inverse associations of fish consumption with birth outcomes ${ }^{(16,18,38)}$. In a study in Denmark, regular fatty-fish consumption was associated with increased maternal plasma concentrations of $\mathrm{PCB}^{(17)}$. These maternal plasma PCB concentrations were associated with lower birth weight in this Danish study, as well as in other studies conducted in Japan, Slovakia, the USA and Sweden ${ }^{(42-46)}$. In The Netherlands, fish consumption contributes on average to up to $26 \%$ of total PCB intake and $12 \%$ of dioxin intake ${ }^{(47,48)}$. In line with the results from previous studies, PCB concentrations in maternal and cord blood have been associated with lower birth weight in The Netherlands as well ${ }^{(49)}$. The present study, however, was conducted in 1998, when PCB levels were considerably higher. Contrary, in the study of Mendez et $a l .{ }^{(38)}$, adjustment for blood levels of $\mathrm{Hg}$ and PCB did not change, and thus explained the inverse associations between fish consumption and birth outcomes. Some other studies also did not observe associations of maternal plasma PCB concentrations with birth weight ${ }^{(50-52)}$. Direct comparison of the effects of contamination by either $\mathrm{Hg}$, dioxins or PCB is complicated due to different levels of contamination between countries, areas and within fish species $^{(48)}$. Dioxin and PCB concentrations in mussels, shrimps, mackerel and cod in The Netherlands are comparable with reported levels in other northern European countries, but higher as compared with levels in Spain $^{(53)}$. Furthermore, there seems to be a downward trend in concentrations of contaminants. A continuous decline, although levelling off, of dioxin and PCB concentrations has been shown in both the Dutch river systems, food and breast milk ${ }^{(47,48,53)}$. The latter might reflect concentrations in the human body ${ }^{(48,54)}$. Also, it appeared recently that when measuring plasma dioxin and PCB concentrations, timing of blood sampling around the time of conception plays an important role ${ }^{(55)}$. Furthermore, differences in the results between studies may be explained by specific congeners assessed, since it is suggested that 
especially anti-oestrogenic PCB are associated with lower birth weight ${ }^{(55)}$.

\section{Methodological considerations}

The strength of the present study is that we assessed fetal growth by actually measuring fetal growth characteristics in the second and third trimesters of pregnancy instead of using only birth outcomes as a proxy for fetal growth. We prospectively collected detailed information on consumption of different fish types, which enabled us to separate the analyses. Also, from our questionnaires, we were able to extensively collect information on many potential confounding variables. A limitation of the study is that we did not have biomarkers on $\mathrm{Hg}$ or other chemical exposures. Therefore, we were not able to separate harmful effects of pollutants from potential beneficial effects of fish consumption. Also, since we assessed fish consumption by categories of fish types, we were not able to assess separate effects of consumption of each different fish species or to recombine specific fish species. Furthermore, since $87 \%$ of eligible mothers completed the FFQ, we may have introduced some bias by missing data. Effect estimates could be biased if the associations of fish consumption with fetal outcomes differ between mothers included and not included in the study population. This seems unlikely, but cannot be excluded.

\section{Conclusions and future studies}

In a population which is relatively low in exposure to fish consumption, we observed no consistent associations of total-fish consumption and consumption of different types of fish with fetal growth characteristics or the risk of neonatal complications. Further studies are required focusing on the association between fish consumption and fetal growth measured by ultrasound. Monitoring contaminants in fish and analysis of additional contaminants, especially congeners having anti-estorgenic activity, might help to further elucidate potential associations.

\section{Acknowledgements}

The Generation R Study is conducted by the Erasmus Medical Centre in close collaboration with the School of Law and the Faculty of Social Sciences at the Erasmus University, Rotterdam, the Municipal Health Service, Rotterdam area, and the Stichting Trombosedienst and Artsenlaboratorium Rijnmond (Star-MDC), Rotterdam. We gratefully acknowledge the contribution of general practitioners, hospitals, midwives and pharmacies in Rotterdam. The general design of the Generation $\mathrm{R}$ Study was made possible by financial support from the Erasmus Medical Centre, Rotterdam, the Erasmus University, Rotterdam, the Dutch Ministry of Health, Welfare and Sport, and The Netherlands Organization for Health Research and
Development (ZonMw). H. T. was supported by a research grant from the European Community's 7th Framework Programme (FP7/2008-2013) under grant agreement no. 212652 (NUTRIMENTHE Project 'The Effect of Diet on the Mental Performance of Children'). V. W. V. J. received an additional grant from The Netherlands Organization for Health Research and Development (ZonMw 90700303). None of the authors had a financial or personal conflict of interest related to the content of the study. All authors have made substantial contribution to the present study and to the writing and editing of the manuscript. Additional contributions are as follows: D. H. M. H. was involved in the planning of the study, statistical analyses, interpretation of the data and drafted the manuscript; S. T. and H. d. B. contributed to the acquisition of the data; V. W. V. J. contributed to the design of the study, supervision, interpretation of the data and critical review of the manuscript; E. A. P. S., H. T. and S. T. had critical input into the manuscript; A. H. conceptionalised the Generation R study and participated in its design and conduction. All authors read and approved the final manuscript.

\section{References}

1. Olsen SF \& Joensen HD (1985) High liveborn birth weights in the Faroes: a comparison between birth weights in the Faroes and in Denmark. I Epidemiol Community Health 39, 27-32.

2. Olsen SF, Hansen HS, Sorensen TI, et al. (1986) Intake of marine fat, rich in (n-3)-polyunsaturated fatty acids, may increase birthweight by prolonging gestation. Lancet ii, 367-369.

3. Olsen SF, Hansen HS, Sommer S, et al. (1991) Gestational age in relation to marine $n-3$ fatty acids in maternal erythrocytes: a study of women in the Faroe Islands and Denmark. Am J Obstet Gynecol 164, 1203-1209.

4. Olsen SF, Grandjean P, Weihe P, et al. (1993) Frequency of seafood intake in pregnancy as a determinant of birth weight: evidence for a dose dependent relationship. J Epidemiol Community Health 47, 436-440.

5. Philibert A, Vanier C, Abdelouahab N, et al. (2006) Fish intake and serum fatty acid profiles from freshwater fish. Am J Clin Nutr 84, 1299-1307.

6. Innis SM (2003) Perinatal biochemistry and physiology of long-chain polyunsaturated fatty acids. J Pediatr 143, S1-S8.

7. Uauy R, Calderon F \& Mena P (2001) Essential fatty acids in somatic growth and brain development. World Rev Nutr Diet 89, 134-160.

8. Szajewska H, Horvath A \& Koletzko B (2006) Effect of $n$-3 long-chain polyunsaturated fatty acid supplementation of women with low-risk pregnancies on pregnancy outcomes and growth measures at birth: a meta-analysis of randomized controlled trials. Am J Clin Nutr 83, 1337-1344.

9. Olsen SF, Osterdal ML, Salvig JD, et al. (2006) Duration of pregnancy in relation to seafood intake during early and mid pregnancy: prospective cohort. Eur J Epidemiol 21 , 749-758.

10. Olsen SF (2004) Is supplementation with marine omega-3 fatty acids during pregnancy a useful tool in the prevention of preterm birth? Clin Obstet Gynecol 47, 768-774, discussion $881-762$. 
11. Hansen HS \& Olsen SF (1988) Dietary (n-3)-fatty acids, prostaglandins, and prolonged gestation in humans. Prog Clin Biol Res 282, 305-317.

12. Sorensen JD, Olsen SF, Pedersen AK, et al. (1993) Effects of fish oil supplementation in the third trimester of pregnancy on prostacyclin and thromboxane production. Am J Obstet Gynecol 168, 915-922.

13. Olsen SF (1994) Further on the association between retarded foetal growth and adult cardiovascular disease. Could low intake or marine diets be a common cause? J Clin Epidemiol 47, 565-569.

14. Mahaffey KR (2004) Fish and shellfish as dietary sources of methylmercury and the omega- 3 fatty acids, eicosahexaenoic acid and docosahexaenoic acid: risks and benefits. Environ Res 95, 414-428.

15. Ramon R, Murcia M, Ballester F, et al. (2008) Prenatal exposure to mercury in a prospective mother-infant cohort study in a Mediterranean area, Valencia, Spain. Sci Total Environ 392, 69-78.

16. Ramon R, Ballester F, Aguinagalde X, et al. (2009) Fish consumption during pregnancy, prenatal mercury exposure, and anthropometric measures at birth in a prospective motherinfant cohort study in Spain. Am J Clin Nutr 90, 1047-1055.

17. Halldorsson TI, Thorsdottir I, Meltzer HM, et al. (2008) Linking exposure to polychlorinated biphenyls with fatty fish consumption and reduced fetal growth among Danish pregnant women: a cause for concern? Am J Epidemiol 168, 958-965.

18. Halldorsson TI, Meltzer HM, Thorsdottir I, et al. (2007) Is high consumption of fatty fish during pregnancy a risk factor for fetal growth retardation? A study of 44,824 Danish pregnant women. Am J Epidemiol 166, 687-696.

19. Rogers I, Emmett P, Ness A, et al. (2004) Maternal fish intake in late pregnancy and the frequency of low birth weight and intrauterine growth retardation in a cohort of British infants. J Epidemiol Community Health 58, 486-492.

20. Buck GM, Tee GP, Fitzgerald EF, et al. (2003) Maternal fish consumption and infant birth size and gestation: New York State Angler Cohort Study. Environ Health 2, 7.

21. Drouillet P, Kaminski M, De Lauzon-Guillain B, et al. (2009) Association between maternal seafood consumption before pregnancy and fetal growth: evidence for an association in overweight women. The EDEN mother-child cohort. Paediatr Perinat Epidemiol 23, 76-86.

22. Oken E, Kleinman KP, Olsen SF, et al. (2004) Associations of seafood and elongated $n-3$ fatty acid intake with fetal growth and length of gestation: results from a US pregnancy cohort. Am J Epidemiol 160, 774-783.

23. Guldner L, Monfort C, Rouget F, et al. (2007) Maternal fish and shellfish intake and pregnancy outcomes: a prospective cohort study in Brittany, France. Environ Health 6, 33.

24. Jaddoe VW, van Duijn CM, van der Heijden AJ, et al. (2008) The Generation R Study: design and cohort update until the age of 4 years. Eur J Epidemiol 23, 801-811.

25. Jaddoe VW, Bakker R, van Duijn CM, et al. (2007) The Generation R Study Biobank: a resource for epidemiological studies in children and their parents. Eur J Epidemiol 22, 917-923.

26. Klipstein-Grobusch K, den Breeijen JH, Goldbohm RA, et al. (1998) Dietary assessment in the elderly: validation of a semiquantitative food frequency questionnaire. Eur J Clin Nutr 52, 588-596.

27. Donders-Engelen M, Van Der Heijden L \& Hulshof K (2003) Maten Gewichten Codenummers (Measures Weights Code Numbers). Wageningen, The Netherlands: Vakgroep Humane Voeding, Landbouwuniversiteit. Wageningen en TNO Voeding Zeist.
28. Netherlands-Nutrition-Centre (2006) Nevo: Dutch Food Composition Database 2006. The Hague: Netherlands Nutrition Centre.

29. Verburg BO, Steegers EA, De Ridder M, et al. (2008) New charts for ultrasound dating of pregnancy and assessment of fetal growth: longitudinal data from a population-based cohort study. Ultrasound Obstet Gynecol 31, 388-396.

30. Hadlock FP, Harrist RB, Sharman RS, et al. (1985) Estimation of fetal weight with the use of head, body, and femur measurements - a prospective study. Am J Obstet Gynecol 151, 333-337.

31. Bakker R, Steegers EA, Obradov A, et al. (2010) Maternal caffeine intake from coffee and tea, fetal growth, and the risks of adverse birth outcomes: the Generation R Study. Am J Clin Nutr 91, 1691-1698.

32. Pena IC, Teberg AJ \& Finello KM (1988) The premature small-for-gestational-age infant during the first year of life: comparison by birth weight and gestational age. J Pediatr 113, 1066-1073.

33. Barker DJ (2006) Adult consequences of fetal growth restriction. Clin Obstet Gynecol 49, 270-283.

34. Ay L, Kruithof CJ, Bakker R, et al. (2009) Maternal anthropometrics are associated with fetal size in different periods of pregnancy and at birth. The Generation R Study. BJOG 116, 953-963.

35. de Goede J, Geleijnse JM, Boer JM, et al. (2010) Marine (n-3) fatty acids, fish consumption, and the 10-year risk of fatal and nonfatal coronary heart disease in a large population of Dutch adults with low fish intake. $J$ Nutr 140, 1023-1028.

36. Anonymous (1998) Zo eet Nederland 1998. Resultaten van de Voedselconsumptiepeiling 1997-1998 (Results of the Dutch National Food Consumption Survey 1997-1998). Den Haag: Voedingscentrum.

37. Welch AA, Lund E, Amiano P, et al. (2002) Variability of fish consumption within the 10 European countries participating in the European Investigation into Cancer and Nutrition (EPIC) study. Public Health Nutr 5, 1273-1285.

38. Mendez MA, Plana E, Guxens M, et al. (2010) Seafood consumption in pregnancy and infant size at birth: results from a prospective Spanish cohort. $J$ Epidemiol Community Health 64, 216-222.

39. Olsen SF \& Secher NJ (2002) Low consumption of seafood in early pregnancy as a risk factor for preterm delivery: prospective cohort study. BMJ 324, 447.

40. Thorsdottir I, Birgisdottir BE, Halldorsdottir S, et al. (2004) Association of fish and fish liver oil intake in pregnancy with infant size at birth among women of normal weight before pregnancy in a fishing community. Am J Epidemiol 160, 460-465.

41. Donahue SM, Rifas-Shiman SL, Olsen SF, et al. (2009) Associations of maternal prenatal dietary intake of $n-3$ and $n$ - 6 fatty acids with maternal and umbilical cord blood levels. Prostaglandins Leukot Essent Fatty Acids 80, 289-296.

42. Konishi K, Sasaki S, Kato S, et al. (2009) Prenatal exposure to PCDDs/PCDFs and dioxin-like PCBs in relation to birth weight. Environ Res 109, 906-913.

43. Sagiv SK, Tolbert PE, Altshul LM, et al. (2007) Organochlorine exposures during pregnancy and infant size at birth. Epidemiology 18, 120-129.

44. Sonneborn D, Park HY, Petrik J, et al. (2008) Prenatal polychlorinated biphenyl exposures in eastern Slovakia modify effects of social factors on birthweight. Paediatr Perinat Epidemiol 22, 202-213.

45. Hertz-Picciotto I, Charles MJ, James RA, et al. (2005) In utero polychlorinated biphenyl exposures in relation to fetal and early childhood growth. Epidemiology 16, 648-656. 
46. Rylander L, Stromberg U, Dyremark E, et al. (1998) Polychlorinated biphenyls in blood plasma among Swedish female fish consumers in relation to low birth weight. $A m \mathrm{~J}$ Epidemiol 147, 493-502.

47. Baars AJ, Bakker MI, Baumann RA, et al. (2004) Dioxins, dioxin-like PCBs and non-dioxin-like PCBs in foodstuffs: occurrence and dietary intake in The Netherlands. Toxicol Lett 151, 51-61.

48. De Mul A, Bakker MI, Zeilmaker MJ, et al. (2008) Dietary exposure to dioxins and dioxin-like PCBs in The Netherlands anno 2004. Regul Toxicol Pharmacol 51, 278-287.

49. Patandin S, Koopman-Esseboom C, de Ridder MA, et al. (1998) Effects of environmental exposure to polychlorinated biphenyls and dioxins on birth size and growth in Dutch children. Pediatr Res 44, 538-545.

50. Grandjean P, Bjerve KS, Weihe P, et al. (2001) Birthweight in a fishing community: significance of essential fatty acids and marine food contaminants. Int J Epidemiol 30, 1272-1278.

51. Longnecker MP, Klebanoff MA, Brock JW, et al. (2005) Maternal levels of polychlorinated biphenyls in relation to preterm and small-for-gestational-age birth. Epidemiology 16, 641-647.

52. Weisskopf MG, Anderson HA, Hanrahan LP, et al. (2005) Maternal exposure to Great Lakes sport-caught fish and dichlorodiphenyl dichloroethylene, but not polychlorinated biphenyls, is associated with reduced birth weight. Environ Res 97, 149-162.

53. van Leeuwen SP, Leonards PE, Traag WA, et al. (2007) Polychlorinated dibenzo-p-dioxins, dibenzofurans and biphenyls in fish from The Netherlands: concentrations, profiles and comparison with DR CALUX bioassay results. Anal Bioanal Chem 389, 321-333.

54. Polder A, Thomsen C, Lindstrom G, et al. (2008) Levels and temporal trends of chlorinated pesticides, polychlorinated biphenyls and brominated flame retardants in individual human breast milk samples from Northern and Southern Norway. Chemosphere 73, 14-23.

55. Murphy LE, Gollenberg AL, Buck Louis GM, et al. (2010) Maternal serum preconception polychlorinated biphenyl concentrations and infant birth weight. Environ Health Perspect 118, 297-302. 